\section{"VÔLEI MASCULINO É PRA HOMEM": REPRESENTAÇÕES DO HOMOSSEXUAL E DO TORCEDOR A PARTIR DE UM EPISÓDIO DE HOMOFOBIA}

\author{
"MEN'S VOLLEYBALL ARE FOR MEN": REPRESENTATIONS OF THE \\ HOMOSEXUAL AND THE SUPPORTER ON AN EPISODE OF HOMOPHOBIA
}

L"VOLEIBOL MASCULINO ES PARA LOS HOMBRES": REPRESENTACIONES DEL HOMOSEXUAL Y DE LOS HINCHAS EN UN EPISODIO DE HOMOFOBIA

\section{Luiza Aguiar dos Anjos*}

Resumo: Com base em um episódio de homofobia ocorrido em uma partida de vôlei, esse trabalho analisa as representações construídas das categorias "homossexual" e "torcedor", utilizando como fonte textos acerca desse caso, veiculados em alguns sites de jornais de grande circulação nacional. Entendendo a representação como o produto da atribuição de sentido que damos às coisas, problematizamos os argumentos utilizados para a construção das representações encontradas que, em sua maioria, são pautados em estereótipos dos esportes e das homossexualidades que, regulados por redes de poder, são tidos como verdades naturalmente estabelecidas.
Keywords

Homosexuality.

Homophobia.

Sports.

Mass media.
Abstract: Based on an episode of homophobia that took place in a volleyball match, this paper examines representations of the categories of "homosexual" and "fan". Its sources were texts published about the case on websites of newspapers of nationwide circulation. Understanding representation as a product of meaning ascribed to things, we discuss the arguments used to construct the representations found - which are mostly guided by stereotypes of sports and the homosexualities that, regulated by power networks, are taken as naturally established truths.

Resumen: Basado en un episodio de homofobia ocurrido en un partido de voleibol, este trabajo analiza las representaciones construidas de las categorías "homosexual" e "hinchada", utilizando como fuente textos sobre ese hecho vehiculados en algunos sites de diarios de gran circulación nacional. Entendiendo la representación como el producto de la atribución de sentido que damos a las cosas, problematizamos los argumentos utilizados para la construcción de las representaciones encontradas que, en su mayoría, se guían por estereotipos de los deportes y de las homosexualidades, que, regulados por las redes de poder, son tomados como verdades naturalmente establecidas.

*Universidade Federal do Rio Grande do Sul, Porto Alegre, RS, Brasil. E-mail: luizaaguiardosanjos@gmail.com

Recebido em: 21-10-2013 Aprovado em: 18-08-2014 \section{comunicación de masas. \\ Homosexualidad. Homofobia. Deportes.}




\section{ROMPENDO MOMENTANEAMENTE O SILÊNCIO}

No dia primeiro de abril de 2011, no Ginásio Poliesportivo do Riacho, em Contagem, Minas Gerais, as equipes Sada Cruzeiro (MG) e Vôlei Futuro (SP) se enfrentavam no primeiro jogo da semifinal da Superliga Masculina de Vôlei. Havia grande expectativa por ambos os lados, pois o vencedor do embate de três jogos garantiria, pela primeira vez, uma vaga na final do torneio. Não foi, contudo, o esperado confronto dentro de quadra que marcou os noticiários esportivos nos dias que se seguiram, mas sim as manifestações vindas das arquibancadas. Durante o jogo, um coro praticamente uníssono de torcedores da equipe mineira ofendia constantemente o jogador adversário Michael, fazendo uso de expressões homofóbicas.

A partir dessa primeira ocorrência, a homofobia e as homossexualidades no esporte passaram a ser pauta nos meios de comunicação durante semanas. Momentaneamente, o fato rompeu com a prática comum de se evitar a discussão do tema. As homossexualidades, sobretudo no campo esportivo, parecem ser consideradas demasiadamente indesejáveis ou intoleráveis para se tornarem notícia, mantendo-se, assim, sob o silêncio, como algo marcado para não ser percebido ${ }^{1}$ (MOUILLAUD, 1997). Utilizando como corpus as repercussões que cercam o "caso Michael", acesso, portanto, uma série de representações acerca das homossexualidades e do esporte que, no cotidiano, têm pequena visibilidade. Tratando-se de um recorte de minha dissertação de mestrado, as fontes empregadas neste artigo foram os comentários das matérias de sites de alguns jornais de grande circulação², sendo eles: Estado de Minas, O Estado de S. Paulo, Folha de S. Paulo e O Globo. Esta pesquisa tem caráter qualitativo, não tendo a pretensão de que essa seleção de fontes abarque impressões generalizáveis sobre o episódio em questão. Acredito, contudo, que contém um volume suficiente de textos para levantar discussões relevantes no que tange a questões de gênero e sexualidade por ele tensionados.

A partir de uma organização do material em categorias criadas a partir do conteúdo encontrado, a análise dos dados é feita na perspectiva de uma abordagem discursiva (HALL, 1997), fazendo uso da noção foucaultiana de discurso. Dentro dessa perspectiva, o discurso está necessariamente associado ao poder e à constituição de saberes. Assim, os textos analisados são vistos como discursos que refletem não um mundo "tal como ele é", mas representações, produtos da atribuição de sentidos de tudo que nos cerca. Nesse sentido, uma abordagem discursiva preocupa-se em compreender como o conhecimento produzido pelos discursos relaciona-se com o poder, regulando condutas, construindo identidades e subjetividades e definindo a forma como as coisas são representadas, pensadas, praticadas (HALL, 1997).

Análises das falas encontradas sugeriram que, marcadamente pelo fato de uma das equipes - Sada Cruzeiro - ser ligada a um clube de futebol - Cruzeiro Esporte Clube -, uma série de questões levantadas era ligada ao esporte bretão. De fato, a criação de uma equipe de vôlei pelo Cruzeiro possivelmente aproximou parte de seus torcedores, tradicionais espectadores de futebol, desse outro esporte. Assim, provavelmente alguns desses passaram a

\footnotetext{
1 É necessário mencionar que, apesar de raras, já houve outras matérias jornalísticas que relataram ou discutiram episódios de homofobia no esporte. Um exemplo são situações envolvendo o jogador de futebol Richarlyson, atualmente no Atlético Mineiro. O atleta, apesar de se afirmar heterossexual, é frequentemente associado à homossexualidade, o que por vezes é citado ou problematizado nos meios de comunicação. Essa questão foi bastante explorada quando o diretor administrativo do Palmeiras, José Cyrillo Junior, insinuou que o jogador seria gay em um programa de televisão, motivando Richarlyson a processá-lo. Na sentença que inocentou o dirigente, o juiz Manoel Maximiano Junqueira Filho afirmou, entre outras coisas, que "futebol é jogo viril, varonil, não homossexual", alimentando o debate. Já no voleibol, quem mais motivou tal discussão foi o ex-jogador Lilico, que se assumiu homossexual em 1999, e também foi alvo frequente de preconceito dos torcedores.

2 As matérias também fizeram parte da análise da dissertação, mas este texto não comportaria uma análise qualificada de ambos.
} 
frequentar os ginásios para torcer, no vôlei, para seu clube de coração. E foi no movimento de entrada do ethos do torcedor de futebol na arena do vôlei que a polêmica envolvendo o jogador Michael emergiu.

Assim, apesar de ter ocorrido em uma quadra de vôlei, esse fato desperta uma série de apontamentos relativos ao comportamento das torcidas de futebol. Nesse sentido, é interessante notar que injúrias semelhantes, que classificam o adversário como homossexual, ou fazem referência à passividade em relações sexuais, ocorrem rotineiramente nos estádios, sem que sejam levantadas discussões ou polêmicas quanto ao seu caráter homofóbico. Foi necessário, assim, outro cenário para que fosse gerado um estranhamento diante das ofensas proferidas.

Como anteriormente dito, tal estranhamento fez com que as manifestações da torcida passassem a ser um acontecimento noticiável. O processo de noticiabilidade, contudo, não é ingênuo nem ocasional. Destacando a intencionalidade da escolha de temas a serem ignorados pelas mídias, Leal e Carvalho (2009) afirmam que "o silêncio e a omissão, pautados pela interdição ou pela indiferença, são tão desumanizadores quanto os xingamentos e a ofensa" (LEAL; CARVALHO, 2009, p. 6).

A inclusão desse episódio na agenda midiática fez com que o ocorrido se tornasse notório a um maior número de pessoas, parte das quais optou por publicizar suas opiniões em fóruns de comentários das reportagens por eles acessadas. Esse texto foca nas representações que os comentários de leitores trazem acerca de dois grupos presentes nesse episódio: homossexuais e torcedores.

O conceito de representação que adoto parte de uma abordagem construcionista, que defende uma separação entre o mundo real e o mundo em que a linguagem, os sentidos e as representações operam simbolicamente (HALL, 1997). Sob essa visão, somos capazes de entender o mundo e atribuir sentidos a ele ao nos comunicarmos por meio de um sistema de representações aproximadamente comum. Ela considera a existência do real e a capacidade de ressignificação pelos sujeitos de significados hegemonicamente colocados, mas não os coloca como responsáveis únicos da formação das representações, e sim dentro de um sistema complexo de interação com a cultura. Esse processo não é apenas técnico, mas sobretudo histórico e político. Assim, as representações podem ser vistas como instrumentos de construção de saberes que, quando impulsionados por tecnologias de poder e controle, assumem o valor de verdade (FOUCAULT, 2012). Nesse sentido, para Foucault (2012), a verdade não existe enquanto valor absoluto, sendo construída e sustentada socialmente por meio dos discursos. Assim, o questionamento de supostas verdades manifestas em certas representações contribui para a desestabilização de um estado de coisas que reprime a multiplicidade das formas de ser e estar no mundo.

\section{GÊNERO, HOMOSSEXUALIDADES E HOMOFOBIA}

De forma simplificada, a homofobia é definida por Daniel Borillo (2001) como a repulsa contra homossexuais, marcada por atitudes de hostilidade, rejeição ou ódio. Nessa manifestação, qualifica-se o outro como contrário, inferior ou anormal. Tal definição parece clara e objetiva. Contudo, perceber o preconceito na prática não parece tarefa tão simples, como se percebe nos textos analisados nesta pesquisa, que transitam por muitos posicionamentos sobre o fato 
das manifestações da torcida cruzeirense terem ou não sido um ato de homofobia.

Concordo com vários teóricos ${ }^{3}$ na crença de que tal incômodo, ou aversão, diante da homossexualidade é fruto de uma construção histórico-cultural que surge enquanto desdobramento da heteronormatividade, entendida como o processo de determinação da heterossexualidade enquanto única opção natural de vivência afetiva e sexual.

A reiteração desse modelo de vivência sexual enquanto um padrão ocorre em função da recomendação, prescrição e fiscalização da sociedade sobre o uso de nossos corpos por meio da família, da escola, das religiões, da ciência, do governo, da lei, etc., que hierarquicamente dividem o certo do errado, o normal do anormal. Essa diferenciação se materializa não apenas em falas e atitudes, mas também na organização de nossos sistemas de saúde, educação, jurídico ou midiático, construídos para atender plenamente apenas os que se adequam ao padrão imposto (LOURO, 2009). Essa dispersão de múltiplos estímulos normativos tem como efeito a naturalização e a ocultação desses mecanismos de controle.

A gestão dos corpos e da sexualidade, enquanto um processo dinâmico e mutável, nem sempre teve os contornos que observamos na contemporaneidade, como mostrou Foucault (1988). Se propondo a traçar uma genealogia da sexualidade, o filósofo demonstrou que, até o século XVIII, apesar de haver certo controle de fronteiras do que era lícito em termos de sexualidade, as infrações eram vistas a partir de sua gravidade, sem distinções acerca de sua natureza. Assim, a sodomia figurava entre os pecados graves, juntamente com o estupro, 0 adultério e o incesto, todos eles passíveis de condenações nos tribunais.

Já no século XIX, ainda segundo Foucault, a sexualidade dos adultos, mesmo que talvez funcionando sob normas mais rigorosas, caminha para uma maior discrição. Figuras anteriormente ignoradas (loucos, crianças, criminosos), por sua vez, são interrogadas, escutadas e condenadas, mas acima de tudo identificadas, de forma a estabelecer os contornos das sexualidades periféricas que limitarão as fronteiras da sexualidade regular. Práticas anteriormente condenadas ganham autonomia, passando a ser analisadas como coisas essencialmente diferentes.

Se, por um lado, a severidade dos códigos impostos pela justiça se atenuou no século XIX, uma outra entidade toma frente no controle dos desvios sexuais: a medicina. Por meio da determinação de um "desenvolvimento normal" e da classificação de patologias e perturbações, ela se torna a maior responsável pela gestão dos desejos. Aqui, o importante a ser analisado não é a transferência de autoridade, mas a alteração dos mecanismos de poder a que se recorre. Não ocasionalmente, é nesse momento, em que o discurso científico toma frente ao discurso religioso - controlado por estruturas jurídicas -, que ocorre o surgimento do homossexual ${ }^{4}$ (FOUCAULT, 1988; LOURO, 2009). Se antes os autores da sodomia eram apenas sujeitos jurídicos, a criação do rótulo, mais do que identificar e nomear, determina a criação de um personagem. Se "o sodomita era um reincidente, agora o homossexual é uma espécie" (FOUCAULT, 1988, p. 51).

Essa nova espécie passa, então, a ser posicionada de forma relacional ante seu oposto direto: o heterossexual. Essa diferenciação e essa classificação, pautadas em discursos científicos e sob o ponto de vista da saúde, moral e higiene, estabelecem ainda uma hierarquia entre

3 Entre diversos, cito Foucault (1988), Borillo (2001), Louro (2009) e Butler (2006).

4 Foucault afirma que uma possível primeira referência do termo é o artigo de Westphal, do ano de 1870. 
as duas categorias, uma forma tida como norma ou padrão e a outra como desvio (LOURO, 2009). Aos desviantes homossexuais, restam, assim, o desprezo, a segregação, a rejeição e a violência.

Para além do controle das práticas sexuais, a matriz hetenormativa impõe referências, também, no campo dos comportamentos e identidades. Isso, pois ela pressupõe que a ideia de masculinidade repousa sobre a repressão necessária de aspectos femininos - do potencial bissexual do sujeito - e introduz o conflito na oposição do masculino e do feminino.

As noções de masculinidade e feminilidade, por sua vez, se relacionam ao conceito de gênero, entendido aqui como uma construção social e histórica dos sujeitos masculinos e femininos, produzida dentro de relações de poder (LOURO, 1997). Entre as expectativas sociais em relação à forma como homens devem se comportar está o seu envolvimento em atividades competitivas e fisicamente intensas, como os esportes. As mulheres, por sua vez, associadas à fragilidade e à sensibilidade, são incentivadas a se envolver em práticas consideradas mais delicadas. Para desconstruir visões essencialistas desse processo, no qual tais formas de inserção no mundo seriam fruto de aptidões ou preferências naturais distintas entre homens e mulheres, Butler (2006) utiliza o conceito de performatividade. Para a autora, o gênero é construído sob uma expectativa, que acaba por produzir uma espécie de essência a ser descoberta. Essa expectativa incentiva, e até mesmo constrange, o engajamento constantemente repetido em determinados comportamentos, valores e ideais, por fim produzindo o exato fenômeno previsto. Assim, é a própria antecipação do gênero que acaba por produzir aquilo que se postula estar fora do sujeito.

Butler (2006) aponta ainda que, sob a condição da heterossexualidade normativa, policiar o gênero é, por vezes, usado como forma de assegurar a heterossexualidade. Esse instrumento regulativo se constrói a partir da expectativa de uma coerência entre as categorias sexo, gênero e sexualidade. Sob essa lógica, homens (machos) necessariamente deveriam desenvolver afetos e desejos por mulheres (heterossexuais) e possuir características ligadas à virilidade e à agressividade (masculinos). As mulheres (fêmeas), por sua vez, deveriam ser sexualmente e afetivamente atraídas por homens (heterossexuais) e ter traços ligados à sensibilidade e à graciosidade (feminilidade).

No episódio analisado neste trabalho, a crença nessa relação de linearidade é bastante evidenciada, como é possível verificar nos trechos: "ekaliu alencar: Ele não é gay??? Porque sentir-se ofendido se o chamam de bicha? Se o chamassem de homem, homem, homem...aí sim ele deveria ficar ofendido, já que estariam contrariando sua vontade ("orientação") sexual" (BASTOS, 2011).

Na citação acima o termo homem é utilizado para se referir a um indivíduo heterossexual do sexo masculino. Assim, sexo e sexualidade são entendidos quase como uma categoria única, gerando um novo binarismo: homem/gay. Fixados no alinhamento sexo-gênero e no binarismo homem-mulher, alguns leitores-comentaristas acabam por definir o homossexual como um indefinido, um sem lugar, como no trecho a seguir:

Ronaldo Mitt: Uma coisa básica. Quando fiz o cadastro no UOL para fazer este comentário, me perguntaram pelo sexo; masculino ou feminino. Perceberam a sutileza? Não existe outro. Se o cara opta por ser gay, não tem problema, aliás, é problema dele. [...](EQUIPES..., 2011). 
Tais discursos, que afirmam a suposta impossibilidade de ser gay e homem simultaneamente, são formas simbólicas de enfatizar 0 afastamento entre homossexuais e heterossexuais masculinos. $O$ leitor-comentarista utiliza o cadastro do UOL para expor a organização binária presente em tantos outros contextos sociais que, para ele, não comporta os homossexuais. Na defesa de Ronaldo Mitt, a situação de abjeto de Michael seria um problema ocasionado por sua opção.

Outro conjunto de falas defende que um homem gay, uma vez se relacionando afetivamente com outros homens, passa a se identificar enquanto mulher, devendo apresentar interesses supostamente adequados a elas. Watch Tower: "Se o cara é uma moça e quer que a torcida fique calada, vai dançar balé" (VÔLEl..., 2011).

Ainda que se reconheça a possibilidade da ironia em tais falas, há uma reiteração de que os valores associados aos homossexuais são os hegemonicamente ligados ao feminino - sensibilidade, vaidade, fragilidade -, novamente reforçando a diferenciação entre homens homossexuais e heterossexuais.

Vale mencionar que a associação entre homossexualidade e feminilidade encontrada em alguns dos textos analisados, tal como nessa citação, foi sempre acompanhada de uma perspectiva essencialista de gênero, na qual as mulheres - e, nesse contexto, por consequência, os homossexuais masculinos - não seriam capazes de praticar atividades fisicamente demandantes, agressivas e competitivas, como é o esporte. Assim, para compreender a complexidade dos conflitos presentes no episódio analisado, é necessário avaliar questões de gênero e sexualidade de forma imbricada.

Encontrei, ainda, alguns leitores que questionam a legitimidade da reivindicação dos direitos pelos homossexuais, baseados em certas representações negativizadas desse grupo:

Gil Queiroz: Não se esqueça, minorias que pregam a depravação sexual como se fosse normal, que querem aparecer vestidos de drag queen, ficam se pegando em qualquer lugar, adoram gritar e dar ataques de histeria e euforia em público, andam pelados pelas ruas, fazem festas onde tudo pode (drogas, fumo, bebidas, sexo), paradas gays que mais parecem as orgias de Roma atualizadas, e aí quando voltam a si mesmos por alguns minutos, vem exigir direitos de igualdade, dignidade, PLC $122^{5}$, cassação de deputado. (BASTOS, 2011)

Percebe-se que, para esse leitor-comentarista, os homossexuais estão relacionados a todo tipo de depravação. A descrição feita demonstra o preconceito enraizado em estereótipos que relacionam o gay a uma pessoa de comportamento reprovável. Sob esse argumento, o leitor-comentarista parece propor que os homossexuais justificam a rejeição e o preconceito que recebem devido a seu comportamento "inapropriado".

Também são encontrados leitores que defendem a perspectiva da homossexualidade enquanto doença.

André Duque Grijó: Se querem tornar o homossexualismo uma coisa normal então que tornem também normal a demência, o psicopata, o pedófilo e todas as doenças associadas a distúrbios de personalidade pois isso não é normal e nunca será perante a natureza humana!!! (EQUIPES..., 2011)

Percebe-se, assim, que ainda há fortes marcas de argumentos médicos e biológicos que há décadas serviam para proclamar a proibição da homossexualidade. Contudo, também

5 Projeto de lei que criminaliza a homofobia. 
o posicionamento da Organização Mundial de Saúde, que retirou a homossexualidade - chamada então de homossexualismo ${ }^{6}$ - de sua lista de doenças mentais, é lembrado por um leitor-comentarista:

Rodrigo Santos: Consulte o site da OMS. Não há doença ou distúrbio, bróder. Se quer afirmar com base em ciência, seja científico: pesquise. [...] Acho válido informar que no restante do reino animal (grupo de seres vivos a que pertencemos), existem outras espécies com indivíduos homossexuais, confira. (EQUIPES..., 2011)

O exemplo citado é um dos poucos nos quais algum leitor-comentarista busca desconstruir um discurso anterior que se baseia em perspectivas heteronormativas para definir os homossexuais. Ainda que outros sujeitos tenham criticado as manifestações da torcida cruzeirense, pregando o respeito e a tolerância, são raros os questionamentos de representações restritas e preconceituosas dos homossexuais apresentadas. Assim, nos textos analisados nessa pesquisa, o homossexual é estabelecido marcadamente como o Outro.

\section{TORCEDOR E SUA MASCULINIDADE COMPULSÓRIA}

Apesar da sociedade em que vivemos já apresentar fortes padrões heteronormativos, as arenas esportivas destacam-se como espaço em que há maior permissividade para expressar tais construções de formas explícitas, ofensivas e agressivas. Assim, parece que, nesse ambiente, as normas que mantêm o alinhamento sexo-gênero-desejo possuem certa especificidade. Essa hipótese é reforçada nos textos analisados nesta pesquisa, que, para justificar a naturalidade do ocorrido no episódio Michael, recorrem a argumentos ligados à constituição do cenário esportivo, como "isso é a forma como a torcida tradicionalmente torce", "o jogador deve estar preparado para ser ofendido", "casos como esse acontecem com frequência", etc.

A naturalização da homofobia ocorre em conjunto com outras formas de preconceito e agressividade verbal e física que são tidas como normais nesses espaços. Cabe, contudo, perguntar como tal entendimento se legitimou ao longo da constituição social do que chamamos de esporte.

O esporte é um fenômeno moderno surgido do século XVIII, e mais marcadamente no século XIX, na Europa, em especial na Inglaterra (BRACHT, 1997). Ele teria surgido, segundo Bracht (1997) a partir da regulação (esportivização) de elementos da cultura corporal, tanto de origem popular quanto das elites, entre os quais os jogos populares são os exemplos mais recorrentes. Junto à urbanização e à industrialização, o esporte desenvolveu-se e disseminou-se, para além dos limites europeus, como símbolo do novo e do moderno, de certa forma negando os valores dos tempos que o precediam.

Elias e Dunning (1992) entendem que, nesse momento germinal do esporte moderno, essa manifestação emerge enquanto formas abrandadas de confronto, no qual são inseridos instrumentos de controle à violência mais rígidos do que os presentes em passatempos populares preexistentes. Assim, os autores demonstram que, desde o seu surgimento, o esporte moderno baseia-se no conflito, se apoiando no difícil equilíbrio entre o enfado e a violência.

Toledo (2002) também corrobora o entendimento de que o esporte é capaz de constituir-se enquanto espaço diferenciado, no qual formas de expressão de emoções são controla-

60 termo homossexualismo era usado para se referir à doença, perversão, transtorno ou distúrbio com que a homossexualidade era identificada pela medicina, especialmente a partir do final do século XIX. Pela remissão patológica, o movimento LGBT brasileiro buscou extirpar o termo de qualquer referência à homossexualidade. 
das sob outros moldes, mais flexíveis. Nesse sentido, ao analisar o futebol, ele defende que a natureza dos comportamentos em uma partida é de ordem ritual, em oposição a outras vivências sociais, que são de natureza cotidiana. É esse caráter ritualístico que legitimaria certas práticas consideradas incomuns em outros espaços ou atividades, entre elas as manifestações de agressividade.

A emergência de estados emocionais diversos pode ser percebida não só na prática do esporte, mas também em sua assistência. Lembremos que, já há séculos, multidões se reuniam para assistir a peças teatrais ou confrontos de gladiadores como forma de diversão. Também, então, na posição de plateia somos convidados a transitar em diferentes estados de espírito, expressando-os de diversas formas. As reações dependem não apenas do espetáculo assistido, mas, sobretudo, da relação que se estabelece com ele. Nesse sentido, quando leitores-comentaristas demandam a legitimidade dos xingamentos em uma arena esportiva, eles parecem demonstrar que aquela atitude é parte fundamental da expressão das sensações sentidas durante aquela atividade de lazer.

Isso não as torna, contudo, naturais e inquestionáveis. É pertinente apontar que uma série de práticas que seriam hoje, no contexto em que vivemos, consideradas intoleráveis, como combates entre humanos e animais ou o enforcamento público, já foram formas de divertimento em tempos antigos. Outras dinâmicas de violência, por sua vez, ainda que disfarçadas, ainda hoje são legitimadas como diversão, indicando a complexidade e aparente incoerência de nossos padrões de civilidade. Nesse sentido, posso citar programas veiculados na mídia que expõem imagens de assassinatos e os combates de $\mathrm{MMA}^{7}$.

Percebe-se, novamente, que os significados sociais das manifestações são fruto de uma constituição histórica fluida, em constante modificação, nem sempre coerente ou linear, fazendo com que transformações sociais levem a alterações no quadro de permissividade que se percebe nas arenas esportivas.

De forma geral, contudo, existe certo grau de manutenção de determinados comportamentos com o passar do tempo. Analisando, nesse momento, especificamente práticas ligadas ao torcer, defendo aqui que isso acontece por meio da aprendizagem que ocorre nos diversos contextos sociais relacionados ao esporte. Entendo que essa aprendizagem, apesar de ocorrer sob influência de um mundo culturalmente e socialmente estruturado, não se dá pela transmissão de informações ou saberes outrora descobertos. Assim, a continuidade das tradições se dá por uma espécie de "redescobrimento dirigido", o que Tim Ingold (2010) chama de "educação da atenção". Assim:

[...] a contribuição de cada uma [geração] para a cognoscibilidade da seguinte não se dá pela entrega de um corpo de informação desincorporada e contexto-independente, mas pela criação, através de suas atividades, de contextos ambientais dentro dos quais as sucessoras desenvolvem suas próprias habilidades incorporadas de percepção e ação. Em vez de ter suas capacidades evolutivas recheadas de estruturas que representam aspectos do mundo, os seres humanos emergem como um centro de atenção e agência cujos processos ressoam com os de seu ambiente. (INGOLD, 2010, p. 21)

Sob essa ótica, não há uma essência do torcer que emerge naturalmente no indivíduo, nem mesmo há uma forma de fazê-lo apriorística, fixa, única e estável que é ensinada de uma geração à seguinte. Assim, de forma dinâmica, torcedores de diferentes modalidades esporti-

7 Sigla em inglês para artes marciais mistas (mixed martial arts). 
vas, de diferentes países e de diferentes gerações apoiam seu time de forma mais ou menos entusiasmada, mais ou menos agressiva, entre tantas outras variações. Isso ocorre porque seus aprendizados, processos de educação de atenção e emergências a partir das relações estabelecidas na prática convergiram para pontos diferentes, em seu tempo, espaço e contexto particulares ${ }^{8}$. Assim, ainda que haja certa estabilidade em determinadas práticas, elas não são fruto da fidelidade com que copiamos regras de conduta, e nada garante que algum aspecto não será modificado ao longo do tempo.

Analiso o torcer enquanto a preferência por um clube, materializada em uma relação afetiva e identitária, chamada por Damo (1998) de pertencimento clubístico. Apesar de, teoricamente, haver muitas maneiras de manifestar afeto para com o clube pelo qual se torce, essa construção do ser torcedor acabou por legitimar também formas específicas - representações - do torcer. Assim explicam os leitores-comentaristas:

W P:[...] xingar adversário de bicha ou de outra coisa é comum e faz parte do ambiente dos estádios e ginásios. Não é politicamente correto, mas sempre foi assim. Existe um manual de xingamentos permitidos? Torcer é incentivar o seu time, atrapalhar o time adversário e pressionar o juiz.[...] (VÔLEl..., 2011).

O leitor-comentarista defende que não há precedentes para questionar as manifestações da torcida pelo fato do xingamento "ser comum", "fazer parte do ambiente". É interessante pontuar que, pelo fato dessas expressões agressivas serem atualmente corriqueiras, $w p$ afirma que "sempre foi assim". Esse entendimento é contrariado pelos estudos de Toledo (1993), que aponta que há algum tempo o palavrão era usado, contudo de forma apenas esporádica, e que foi especialmente a partir da década de 1970 que começou a ser proferido em coro e com grande frequência.

Para o leitor-comentarista, ainda, o torcer é descrito a partir de duas ações básicas: incentivar o time e prejudicar 0 adversário ${ }^{9}$. Por essa interpretação, 0 amor ao clube deve ser demonstrado por meios que colaborem para o seu sucesso nas partidas. Assim, as ofensas a Michael são vistas, também, como o cumprimento do papel da torcida para com sua equipe. Assim, quem não age dessa forma não é visto como torcedor, como demonstra o comentário: "Marcio Andrade: Tá provado que vôlei não tem torcida, tem platéia. Ê povo criado a leite com pêra..." (VÔLEI..., 2011).

Márcio Andrade entende que o fato das ofensas contra Michael terem provocado questionamentos demonstra que o público presente não se constitui de torcedores, entre os quais essa forma de manifestação é normal e necessária. Eles seriam, então, uma plateia que, ao assistir a um espetáculo, deve portar-se de forma educada e controlada. Tal grupo é, ainda, desqualificado, tido como "povo criado a leite com pêra", expressão jocosa que se refere a pessoas que receberam zelo excessivo em sua criação, vindo a se tornar adultos mimados e polidos em demasia. Assim, o leitor-comentarista coloca em oposição os mimados espectadores, aos corajosos e viris torcedores.

Ainda sob essa perspectiva, o torcer vai além de um momento individual de diversão, no qual se obtém prazer ao desfrutar de um espetáculo. Ele se relaciona também com as ações

\footnotetext{
8 Importante pontuar que, mesmo dentro de padrões relativamente estáveis (em um mesmo país, analisando grupos de uma mesma classe social e faixa etária, na prática de uma mesma modalidade esportiva, por exemplo), podemos, também, observar nuances e distinções no comportamento.

9 Entendo que as ações de pressão ao juiz podem ser inseridas em ambas as linhas, pois visam tanto ao benefício próprio, quanto ao prejuízo do adversário.
} 
altruístas de dedicação ao time, em prol de seu sucesso e sua honra. Tal entrega apenas se justifica pela relação de vínculo que se estabelece entre clube e torcedor, o já citado pertencimento clubístico.

A permissividade do espaço esportivo é usufruída especialmente pelas manifestações verbais e gestuais do torcedor. Focando na primeira categoria, mais afeita a este estudo, Toledo (1993), em pesquisa na qual analisa a comunicação entre torcedores de futebol, demonstra a forte presença da sexualidade nos palavrões proferidos nos estádios. Ele aponta, ainda, que, enquanto as palavras de incentivo e autoafirmação à sua equipe fazem referência a atributos masculinos de força e virilidade, os de protesto e intimidação ao adversário com frequência referem-se à sua passividade sexual.

Ainda nessa pesquisa, Toledo (1993) identifica que, muitas vezes, atributos utilizados para ofender os torcedores adversários são assumidos por eles, esvaziando seu caráter negativo. É o caso, por exemplo, dos torcedores do Corinthians, que aceitaram os adjetivos de "favelados" e "cachorros", de forma a reforçar sua identificação como time do povo. Contudo, esse processo não é observado quando tratamos de termos que fazem alusão à sexualidade ou à feminilidade. Enquanto um conflito imaginário ${ }^{10}$ de classes entre clubes de elite e clubes de massa pode ser teatralizado na rivalidade entre duas equipes, o mesmo não se percebe quando tratamos de conflitos de gênero ou de sexualidade. A heteronormatividade da sociedade, somada à masculinidade hegemônica associada ao esporte, praticamente impede qualquer torcida de aceitar atributos ligados ao homossexual ou à mulher.

Destaco, assim, que o cerne do questionamento acerca do ocorrido no episódio $\mathrm{Mi}-$ chael não é a conduta da torcida, vista de modo genérico como atos de incentivo ao clube e prejuízo ao adversário, como propuseram alguns leitores-comentaristas previamente citados. $\mathrm{O}$ que gerou tamanho conflito foi o teor das expressões que visavam comprometer o desempenho adversário: o conteúdo homofóbico. Assim, os discursos analisados que criticam a torcida celeste não propõem, necessariamente, uma ruptura nas maneiras estabelecidas de se torcer, mas demandam mudanças, rejeitando uma suposta fixidez e estabilidade desses padrões, havendo um limite para a liberdade de expressão das torcidas.

Em outros comentários, por sua vez, o torcer parece condicionado ao enquadramento do vôlei a determinadas representações de esporte, estabelecendo padrões de comportamento para todos os seus agentes: jogadores, comissão técnica, torcedores, espectadores de TV, cobrados a portar-se de forma coerente com a imagem construída e alimentada dessa modalidade. Foi possível organizar essas representações dentro de dois pares de oposição: esporte de elite $\mathrm{x}$ esporte de massa, e esporte de bicha $\mathrm{x}$ esporte de macho. Em ambos os casos, 0 futebol é utilizado enquanto elemento importante para situar o vôlei.

$\mathrm{Na}$ fala abaixo, temos um exemplo do distanciamento do vôlei e do futebol, sendo 0 primeiro visto como esporte de elite e o segundo como esporte de massa:

Rodolfo Valentino: Um dos piores erros do voleibol é permitir que a torcida de futebol se misture com o público do vôlei. O que é um esporte familiar, saudável em breve pode ser tomado por atos de vandalismo, agressões mútuas, homicídios e toda a barbárie que todos nós conhecemos dos jogos de futebol. (VÔLEI..., 2011) 
O comentário defende que a torcida do vôlei e a do futebol são grupos de pessoas necessariamente diferentes. Enquanto o público do primeiro seria formado por famílias, o do segundo seriam vândalos, agressores, assassinos. Percebe-se, ainda, que, sob o conceito de "esporte familiar", o autor parece afirmar que esse lugar apresenta uma ambiência segura e convidativa para mulheres e crianças, vistas como grupos frágeis. A descrição do que observa no futebol - "tomado por atos de vandalismo, agressões mútuas, homicídios e toda a barbárie" - é colocada, ainda, não como um ponto de vista, mas como uma verdade, ao dizer que é um cenário que "todos nós conhecemos". O torcedor nega, ainda, a possibilidade de que uma mesma pessoa possa interessar-se pelos dois esportes. Em sua visão, torcedores de futebol e de voleibol são necessariamente grupos distintos, formados por pessoas diferentes e com características divergentes.

Outros comentários, por sua vez, situaram o vôlei ao lado do futebol como um esporte de massa, como no seguinte exemplo:

Otavio Viegas: A intenção era desestabilizar o jogador para que seu time perdesse a partida. Só isso. É um jogo de vôlei, e a torcida quer derrubar o time adversário. Não era um jogo de tênis em que os torcedores se comportam como lords. (BASTOS, 2011).

A oposição aí se faz com o tênis, esporte com baixo número de espaços públicos para a prática e com alto custo de equipamentos, dificultando ou inviabilizando a prática pelas camadas populares, justificando o imaginário. Além disso, não é comum que haja vaias ou manifestações visando atrapalhar o atleta adversário. Tal comportamento da torcida é entendido, assim, como típico de um esporte de elite.

Além do enquadramento em esporte de massa ou esporte de elite, outra classificação também foi proposta: esporte de macho x esporte de bicha"1. "Mind Munch: Desde quando torcedor de vôlei tem moral para questionar a orientação sexual de alguém? Hahaha." (EQUIPES..., 2011).

Nos casos acima, o voleibol é enquadrado como um esporte de homossexuais, um esporte de bicha. Como já discutido, defendo que tais associações são fruto de um falso alinhamento sexo-gênero-desejo, além de visões essencialistas e hierarquizadas do gênero. Assim, o homem "verdadeiro" deveria praticar atividades "de homem", esportes de macho, entre os quais o futebol é exemplo recorrente. A fala dos leitores-comentaristas enquadra o vôlei fora desse leque de atividades. Dentro dos padrões de gênero, por conseguinte, o vôlei é considerado uma atividade de mulheres, e, ao praticá-lo, um homem tem, automaticamente, suspeitas levantadas sobre a sexualidade. Dessa forma, segundo propõem os leitores-comentaristas, enquanto prática tipicamente feminina, o vôlei atrairia homossexuais, tanto nas quadras, quanto nas arquibancadas.

Outros comentários, contudo, sem se aterem à questão esporte de bicha $\mathrm{x}$ esporte de macho, defendem que o vôlei masculino deve ser praticado por homens. Contudo, tais apontamentos se valem do alinhamento sexo-gênero-desejo para excluir os homossexuais da categoria homem e, por consequência, do vôlei masculino. "Full Metal Jacket: Vôlei masculino é pra homem." (RIBEIRO, 2011)

11 Proponho o uso de tais termos - macho e bicha - pois foram recorrentemente usados nos comentários de leitores para se referir aos estereótipos do homem heterossexual - agressivo, rude, interessado por práticas físicas - e do homem homossexual - sensível, frágil, efeminado - respectivamente. 
Assim, na citação acima, o leitor-comentarista, ao dizer que o "vôlei masculino é para homens", além de inferir que essa é uma modalidade fechada às mulheres, parece se referir a um modelo específico de homem ao qual Michael não se adequa, por ser homossexual, mas também por ser assumido e não apresentar o estereótipo de virilidade.

Percebe-se, assim, que uma série de valores, não necessariamente unânimes ou coerentes, é associada ao vôlei e ao futebol. Percebe-se, contudo, que existe uma definição do futebol enquanto referencial do esporte de homem e de massa, na qual se legitimam valores associados à masculinidade hegemônica. É sobretudo a aproximação ou o afastamento do vôlei desse referencial que conduz a maior parte dos argumentos a situarem-se como favoráveis ou contrários à manifestação homofóbica da torcida cruzeirense contra Michael.

\section{CONSIDERAÇÕES FINAIS}

Parece-me claro que a construção de padrões que legitimam ou não a participação em determinadas atividades - no caso, atividades esportivas - potencialmente afasta os sujeitos que não se adequam.

Os comentários de leitores analisados nessa pesquisa, ainda que não de forma absolutamente consensual, defenderam que manifestações de homofobia da torcida são expressões coerentes com um modelo hegemônico de esporte, assentado em valores associados à masculinidade hegemônica, como força, virilidade, agressividade, competitividade.

As representações dos homossexuais, por sua vez, além de frequentemente negativizadas, são vistas como o produto de um desvio no esperado alinhamento entre sexo, gênero e sexualidade, os dois últimos sendo prolongamentos naturais do primeiro. Esse suposto desajuste é constantemente reiterado pelos comentários dos leitores, que identificam a homossexualidade como problema, depravação, anormalidade, doença, sobretudo um não-lugar. O posicionamento explícito dos leitores-comentaristas do homossexual como sujeito abjeto corrobora, assim, a normalização da heteronormatividade e da homofobia. 0 ginásio, tanto na quadra como nas arquibancadas, mostrou-se um lugar regulatório e inóspito aos que não se adequam à masculinidade hegemônica, evidenciando uma disputa por modos de vida que podem e/ou devem ser vividos.

Analisar posicionamentos que debatem a legitimidade das manifestações contra Michael é uma atitude útil ao processo de questionamento do preconceito de sexualidade e gênero presente nos ambientes esportivos. Nesse sentido, problematizar discursos que afetados/ produzidos por um rede de poder ganham o status de verdade subsidiando tais formas de regulação faz-se não apenas necessário, mas também urgente. Romper o silêncio é (apenas) o primeiro passo.

\section{REFERÊNCIAS}

BASTOS, Mariana. Vi um ginásio inteiro gritando 'bicha', diz Michael. Folha de S. Paulo, São Paulo, 6 abr. 2011. Disponível em: <http://www1.folha.uol.com.br/esporte/898787-vi-um-ginasio-inteirogritando-bicha-diz-michael.shtml>. Acesso em: 15 jan. 2012.

BORILLO, Daniel. Homofobia. Barcelona: Edicions Bellaterra, 2001. 
BRACHT, Valter. Sociologia crítica do esporte: uma introdução. Vitória: CEFD/UFES, 1997.

BUTLER, Judith. Gender Trouble. New York: Routledge, 2006.

DAMO, Arlei Sander. Para o que der e vier: o pertencimento clubístico no futebol brasileiro através do Grêmio Foot-Ball Porto Alegrense e seus torcedores. 1998. 257f. Dissertação (Mestrado em Antropologia Social) - Instituto de Filosofia e Ciências Humanas, Universidade Federal do Rio Grande do Sul, Porto Alegre, 1998.

ELIAS, Norbert; DUNNING, Eric. A busca da excitação. Lisboa: Difel, 1992.

EQUIPES trocam acusações em caso de homofobia no vôlei. Folha de S. Paulo, São Paulo, 6 abr. 2011. Disponível em: <http://www1.folha.uol.com.br/esporte/899157-equipes-trocam-acusacoes-emcaso-de-homofobia-no-volei.shtml>. Acesso em: 15 jan. 2012.

FOUCAULT, Michel. História da sexualidade 1: a vontade de saber. Rio de Janeiro: Graal, 1988.

FOUCAULT, Michel. Microfísica do poder. 25.ed. São Paulo: Graal, 2012.

INGOLD, Tim. Da transmissão de representações à educação da atenção. Educação, Porto Alegre, v. 33, n. 1, p. 6-25, jan./abr. 2010.

HALL, Stuart. Representation: cultural representations and signifying practices. Londres: Sage Publications, 1997.

LEAL, Bruno Souza; CARVALHO, Carlos Alberto de. Sobre jornalismo e homofobia ou: pensa que é fácil falar? Revista da Associação Nacional dos Programas de Pós-Graduação em Comunicação E-compós, Brasília, v. 12, n. 2, p. 1-5, maio/ago. 2009.

LOURO, Guacira Lopes. Gênero, sexualidade e educação: uma perspectiva pós-estruturalista. Petrópolis: Vozes, 1997.

LOURO, Guacira Lopes. Heteronormatividade e homofobia. In: JUNQUEIRA, Rogério Diniz (Org.). Diversidade sexual na educação: problematizações sobre a homofobia nas escolas. Brasília: Ministério da Educação, Secretaria de Educação Continuada, Alfabetização e Diversidade, UNESCO, 2009.

MOUILLAUD, Maurice. A informação ou a parte da sombra. In: MOUILLAUD, Maurice; PORTO, Sérgio Dayrell (Org.). 0 jornal da forma ao sentido. Brasília: Paralelo 15, 1997.

RIBEIRO, Vicente. Cruzeiro faz a festa da torcida, atropela Vôlei Futuro e chega à decisão inédita. Estado de Minas, Belo Horizonte, 15 abr. 2011. Disponível em: <http://www.superesportes.com.brl app/1,15/2011/04/15/noticia volei,181976/>. Acesso em: 15 jan. 2012.

TOLEDO, Luiz Henrique de. Lógicas no futebol. São Paulo: Hucitec/Fapesp, 2002.

TOLEDO, Luiz Henrique de. Por que xingam os torcedores de futebol? Cadernos de Campo, São Paulo, n. 3, p. 20-29, 1993.

VÔLEl futuro critica multa dada ao Cruzeiro e ironiza STJD. Folha de S. Paulo, São Paulo, 14 abr. 2011. Disponível em: <http://www1.folha.uol.com.br/esporte/902694-volei-futuro-critica-multa-dada-aocruzeiro-e-ironiza-stjd.shtml>. Acesso em: 15 jan. 2012. 